\title{
Reasons for participating and not participating in a e-health workplace physical activity intervention: A qualitative analysis
}

\section{Abstract}

Purpose. This study aimed to investigate the reasons for participating and not participating in an e-health workplace physical activity (PA) intervention.

Methodology. Semi-structured interviews and two focus groups were conducted with a purposive sample of employees who enrolled and participated in the intervention and with those who did not complete enrolment, hence did not participate in it. Data was examined using thematic analysis according to the clusters of "reasons for participation" and for "nonparticipation".

Findings. Reported reasons for participation included a need to be more active, to increase motivation to engage in PA, and to better manage weight. Employees were attracted by the perceived ease of use of the programme and by the promise of receiving reminders. Many felt encouraged to enrol by managers or peers. Reported reasons for non-participation included lack of time, loss of interest towards the programme, or a lack of reminders to complete enrolment.

Practical implications. Future e-health workplace behavioural interventions should consider focusing on employees' needs and motivators to behaviour change, provide regular reminders for participants to complete enrolment and ensure that procedures are completed successfully. Barriers to participation could be identified through formative research with the target population and feasibility studies.

Originality/value. This study combines a qualitative analysis of the reasons why some employees decided to enrol in a workplace PA intervention and why some others did not. This study highlights factors to consider when designing, implementing and promoting similar 
interventions and that could inform strategies to enhance participation in workplace PA interventions.

\section{Acknowledgements}

The authors thank all employees for their participation in the interviews and focus groups, and the workplace health champions of the participating organisations for helping organising the focus groups. This work was supported by the Swiss National Science Foundation grant [Ref. nr. to be provided after peer review].

\section{Introduction}

The rising number of worksite health promotion programmes (WHPP) within the last 30 years demonstrates that the workplace is now well-accepted as an important setting for health promotion (Soler et al., 2010). Reviews and studies on workplace physical activity (PA) interventions have shown that such programmes can demonstrate evidence of effectiveness in changing health behaviour (Abraham and Graham-Rowe, 2009; Conn et al., 2009; Malik et al., 2013; To et al., 2013). The low rates of participation and high rates of attrition often observed in WHPP and PA interventions raise questions about the potential impact of these programmes on the health and wellbeing of the employee population (Geraghty et al., 2013; Robroek et al., 2009).

Some reviews (Dishman et al., 1998; Marshall, 2004; Robroek et al., 2009) showed that participation rates in workplace health promotion programmes vary widely and according to intervention type (e.g., educational programme vs. counselling, fitness vs. general physical activity, etc.). One of the most recent reviews shows that it can range from $10 \%$ to $64 \%$, with median participation of 33\% (Robroek et al., 2009). In workplace PA interventions, participation rate patterns are similar, ranging from $20 \%$ to $80 \%$ of the eligible employee population (To et al., 2013), with some web-delivered interventions reporting similar 
(Robroek et al., 2010) and even lower participation rates (Spittaels et al., 2007). Attrition or drop-out rates are another challenge for web-delivered interventions (Geraghty et al., 2013), and vary across intervention types and settings. Recent review literature indicates that attrition ranges from $9.2 \%$ to $10 \%$ in workplace interventions promoting physical activity and exercise, from $1 \%$ to $65 \%$ in workplace interventions based on counselling, and from $4 \%$ to $56 \%$ in health promotion messages/information interventions (Malik et al., 2013). Given that workplace health promotion is listed among the five priorities of Public Health England in 2013-2014 (PHE, 2013), an improved understanding of the factors which encourage or discourage employees to enrol and participate in WHPP and workplace PA interventions is essential to assist in the design of future programmes which engage a large number of participants.

The literature about participation in workplace health interventions is not extensive. Dishman, Sallis and Orenstein' seminal review on determinants of physical activity (1985), in which they found that participation in physical activity and exercise programmes depended on type of activity (i.e., fitness, exercise or general PA), characteristics of the person and individual lifestyle habits, and environmental characteristics. Linnan and colleagues outlined a social ecological conceptual framework for understanding multiple levels of influence on participation in worksite health programmes (Linnan et al., 2001). The framework distinguishes between individual ("intrapersonal" and "interpersonal”), organisational ("institutional"), community-level or societal, and policy factors. Intrapersonal factors are associated with the individual's characteristics (e.g., gender or other demographic factors), socio-cognitive factors (e.g., beliefs, attitudes, intention, motivation), and personal interest towards the programme. Interpersonal factors encompass for example the role played by coworkers, peers or family members who may encourage participation. Institutional factors are related to the organisation that sponsors the programme and allows or facilitates participation 
in it. Societal and policy factors are of higher order and involve other stakeholders and influencers external to the individual and to the organisation and are often not covered by research interventions (Linnan et al., 2001). These factors conceptually reiterate King et al.'s classification of determinants of participation in physical activity interventions for adults: "personal characteristics", "programme/regimen factors", and "environmental factors", with environmental factors encompassing organisational, societal and policy factors (King et al, 1992). Some research suggests that participation is influenced by individual-level characteristics, such as demographics (e.g., being female, highly educated, white-collar work typology) and socio-cognitive factors, such as high self-efficacy, positive attitudes towards the behaviour, positive intention, and motivation readiness (Kaewthummanukul and Brown, 2006; Robroek et al., 2009). Among programme-related factors, the perceived quality of the communication about the programme positively influences participation (Robinson et al., 2006). Among organisational or environmental factors, employer and managerial support are often reported as positively associated with participation rates (DeJoy et al., 2009; Heinen and Darling, 2009).

Research about participation in workplace health programmes specifically targeting physical activity is even more limited. In WHPP, some studies suggest that participation rates are lowest among younger men, low educated, blue-collar workers, who have low intention to engage in PA and high perceived barriers to PA (Chinn et al., 2006; Lakerveld et al., 2008). Other barriers to participation in programmes include low self-efficacy for exercise (Edmunds et al., 2013), lack of motivation and interest in PA, and the presence of other health problems or requirement for medical treatments that limit their ability to engage in PA (Groeneveld et al., 2009). Known programme-related barriers to participation in programmes include inconvenient locations and time limitations of the programme (Bull et al., 2008; Edmunds et al., 2013; Fletcher et al., 2008; Kruger et al., 2007; Person et al., 2010; Phipps et al., 2010; 
Robroek et al., 2012), and lack or insufficient use of appropriate type of incentives (Person et al., 2010; Phipps et al., 2010). Other studies found that common barriers to participation were forgetting to subscribe, being unaware of the programme itself, or desire to keep personal life separated from work (Joslin et al., 2006; Robroek et al., 2012). Among external factors, major reported barriers to participation were poor physical access to facilities (Bull et al., 2008; Laws et al., 2013), lack of "PA culture" in the workplace and limited employer support (Edmunds et al., 2013).

Whilst there is some understanding of the demographic, socio-cognitive and organisational/environmental determinants of participation and non-participation (Chinn et al., 2006; Groeneveld et al., 2009; Joslin et al., 2006; Lakerveld et al., 2008; Robroek et al., 2012), researchers have not explored fully the reasons why some employees participate and some others decide not to participate. To the best of our knowledge, few studies published to date have investigated the motives for participation and non-participation in workplace PA interventions using qualitative approaches (Edmunds et al., 2013; Fletcher et al., 2008; Phipps et al., 2010). Two US-based studies discussed the reasons for potential participation in future programmes which were not actually offered (Fletcher et al., 2008; Phipps et al., 2010), and only one study has investigated non-participation in an intervention conducted in a single workplace in the UK (Edmunds et al., 2013). Despite investigating the reasons why some people do not participate in workplace PA interventions, none of these studies have investigated the reasons why some employees, who might be interested in the programme, do not complete the enrolment, hence deciding not participate in the study (i.e., early attrition). This study aimed to investigate employees' reasons for participating and not-participating in an actual e-health workplace physical activity intervention offered across 17 UK worksites. The intervention consisted in a 12-week e-mail and text messaging (SMS) communication intervention promoting leisure-time and workplace physical activity among employees of 
participating organisations. Text messages are increasingly used in health promotion interventions in a range of populations, behaviours and settings (Fjeldsoe et al., 2009; Free et al., 2011; Sirriyeh et al., 2010; Wallace et al., 2011), and have been successfully employed also in physical activity promotion (Fanning et al., 2012). The programme was based on a randomised controlled trial (RCT) design with two study groups: the first group received one personalised e-mail message every week, for 12 weeks, whereas the second intervention group received one personalised e-mail and two standard SMS text message reminders every week for 12 weeks. E-mails contained thematic motivational messages encouraging physical activity, designed using Maibach and Parrott's suggestions (Maibach and Parrott, 1995) and were based on the Theory of Planned Behaviour (Ajzen, 1991), while text messages were used as additional motivational prompts, reminding about physical activity and reinforcing the e-mail message. Workplaces participating in the intervention included five academic institutions, four chemical companies, one plastic factory, two Borough Councils, one large telecommunication service company, one small-to-medium IT enterprise, and one insurance company. Workplaces agreed to promote the programme to their employees through posters, brochures and e-mail invitations which linked to the study website at which interested participants signed up to participate. The programme was promoted through the help of workplace health champions and volunteers from each place among a population of more than 32,500 employees, across the 17 workplaces. The estimation were based on data published on websites or online news venues, or were estimated on the basis of interviews with occupational health advisers and workplace health advocates, as the organisations did not provide this information.

To be enrolled in the programme, interested employees were required to visit the programme enrolment website and submit a statement of informed consent online, pass the eligibility criteria and complete a baseline assessment online. Between September 2009 and 
August 2010, a total of 469 employees submitted their informed consent and passed the initial eligibility check (initial enrolment), and 393 successfully completed enrolment by submitting the baseline assessment (83\%) and received the intervention. The remaining 76 employees did not return the baseline questionnaire, so did not complete enrolment, hence did not participate in the study, fact that could be considered an index of early attrition. The present paper investigated the reasons for participating in the intervention for the employees who did not complete enrolment ("non-enrolled employees") and those who successfully completed enrolment (“enrolled employees").

\section{Methods}

\section{Participants and procedures}

The present paper investigates the reasons for participation in the intervention among the segment of 393 "enrolled employees" and the reasons for non-participation among the segment of 76 "non-enrolled employees". Ethical approval for this study was gained from the local institutional review board in May 2011. Between June and July 2011, enrolled employees and non-enrolled employees were invited by email to take part in interviews and focus groups about their participation in the programme, according to the sampling procedures described as follows. Sample recruitment was based on mixed-methods purposive sampling techniques, as recommended by Marcus et al. (2006). Sampling was based on “maximum variation" and "extreme case sampling" (Onwuegbuzie and Collins, 2007; Sandelowski, 2000; Tuckett, 2004). The aim of this was to collect the views and perspectives of a broad variety of enrolled and non-enrolled employees, with different individual characteristics and working from different types of organisations. Since for non-enrolled employees only gender, age and contact information were available, sampling was based on gender and age criteria. Invitation e-mails, containing a study description and a copy of informed consent, were sent to randomly selected sub-groups of both female and male 
employees, until a sufficient proportion of participants in each sub-group (representative of the reference population) was reached and theoretical saturation was achieved in both segments of "enrolled" and "non-enrolled" employees. As the study was implemented in 17 different organisations spread across the United Kingdom, in addition to individual interviews focus groups were organised for practical reasons within organisations that agreed to host them and in which a sufficient number of participants had consented to take part. It was not possible to organise focus groups with non-enrolled employees, as they were too dispersed across worksites and organisation of a group interview was not feasible. The differences in the quality of the data collected through the different interview techniques and the existence of power relations and social influencers were taken into account during data analysis, by separately analysing focus group and interview data. The focus groups were organised with the assistance of workplace health champions, who were employees involved in workplace health promotion initiatives within each of the organisations. The workplace health champions were also participants in the programme. When face-to-face interviews were impractical, interviews were conducted via voice over internet protocol software (Skype).

The first author conducted all interviews and focus groups, which were audio-recorded with permission. After introductions and some ice-breaking questions about past experience with health promotion programmes and physical activity, the interviewer prompted and reminded the interviewees about the programme by showing them sample copies of the posters used for its promotion. This was done to refresh the interviewee's memory, since the interviews and focus groups took place approximately 10 months after the intervention ended. The interviewees were then asked about their reasons for participating or not participating in the programme. An interview guide was developed on the basis of previous experience from all authors, and contained questions aimed at eliciting participants' responses in an open format, for example: "Why did you enrol/not enrol in the programme?", "What were the 
major difficulties you discovered while enrolling", etc. All interviewed participants received a $£ 10$ gift voucher for their time. With enrolled participants, individual interviews typically took 25 minutes to complete (range: 15 - 40 minutes) and focus group interviews lasted about one hour. Interviews with non-enrolled participants lasted, on average, up to 17 minutes (range: 15 - 30 minutes).

\section{Analysis}

Interviews and focus groups were transcribed verbatim using F4 for Windows (provided by audiotranskription.de) and transcripts were analysed in Atlas.ti v6.2.26. Thematic analysis (Ritchie and Lewis, 2003) was employed to analyse the transcripts. Differently from Edmunds and colleagues' (2013) study, who used a grounded theory approach, we utilised an a priori framework derived from the work of Linnan and colleagues (2001) and from King et al.’s (1992) categorisation of determinants of participation in physical activity programmes (i.e., personal characteristics, programme/regimen factors, environmental factors). Reasons were grouped according to two overarching clusters of "Reasons for participation" and "Reasons for non-participation". Within the two clusters, themes were organised according to three main topical areas: 1) “internal reasons"; 2) "programme-related reasons"; 3 ) “external reasons", which respectively resemble the categories of "individual/personal characteristics", "programme/regimen factors", and "organisational/environmental factors".

The first author analysed the interview material and developed a codebook of themes under the abovementioned categories. Considering the potential differences in data collection utilising interviews compared to focus groups (e.g., individual vs. group dynamics in terms of data which is generated), the data was analysed separately. A first codebook was pre-tested with the transcripts from the two focus groups, and then was validated in a subset of 10 interviews. The final version of the codebook was then applied to the full sample of interviews. Final results were cross-checked by the other authors. 


\section{Results}

Forty-two employees who enrolled in the intervention agreed to be interviewed face-toface, and 11 agreed to participate in focus groups. Nine non-enrolled employees agreed to be interviewed. The majority of enrolled employees were working in two large academic institutions, but the sample included also those working in a Borough Council, a large factory, and an insurance company. Focus groups took place in one college and in a chemical company. Non-enrolled employees came from the two academic institutions and from an insurance company.

Characteristics of the interviewed sample are presented in Table 1. The distribution of age, gender, education and workplace type of enrolled employees was representative of the reference population of employees who enrolled in the programme. The majority of interviewees were female $(n=40)$, with a mean age of 39 years, worked full time, had obtained a higher education degree, and lived as a couple with children. For those nonenrolled employees $(n=9)$ the majority was female; the mean age was 36 years for both male and female participants and the composition was similar.

$$
<\text { Insert Table } 1 \text { about here }>>
$$

The topical area named "internal reasons" encompassed reasons associated with the interviewees' perceived needs and motives that encouraged participation (e.g., need to become more physically active, be motivated, etc.) or discouraged it (e.g., perception of having no time). The topical area of "programme-related reasons" included reasons related to characteristics or features of the programme (e.g., perceived attractiveness, ease of use), or that prevented them from enrolling (e.g., perception of being too time consuming). The topical area labelled "external reasons" encompassed factors that were external to the individual and covered other people's influence (e.g., the programme being recommended by a supervisor or colleague), or non-participation (e.g., lack of follow-up by their supervisors). 
Themes are discussed below and schematically summarised with illustrative quotations in

Table 2. The results of the focus groups are presented separately from those of the interviews, but recurring and co-occurring themes are reported with the same headings.

\section{Reasons for participation (focus groups)}

\section{Internal reasons}

Internal reasons concerned the overarching theme of "health-related needs and motivators", which encompassed two sub-themes: weight management and motivation. Weight management was framed in terms of a need to lose weight, which was mentioned both by female and male participants, providing examples from personal experience with being overweight or obese. Losing weight was intended mostly as a need to improve physical appearance in relation with significant others, but was also linked to concerns about general health and wellbeing. Similar to participants' views that emerged in interviews, the second most recurring theme across the two focus groups was linked to the need to get motivated, in order to engage in more physical activity and being fitter and stay healthy.

\section{Programme-related reasons}

Participants joined the programme because they liked the idea of receiving constant reminders by email or via text messaging as they thought these reminders would have helped them do more activities and achieve their goals. In this sense, the fact itself that the programme was delivered via text message and email was perceived as positive, attractive feature for them.

\section{External reasons}

No external reasons explicitly emerged from the focus group discussions. However, this might be because the focus groups were organised with the help of workplace health champions, who were also participants in the interview process and assisted with the 
recruitment of participants in the e-health programme. Therefore, their recommendation and endorsement during the recruitment phase of the programme could be considered implicit environmental factors.

$<$ Insert Table 2 about here >>

\section{Reasons for participation (interviews)}

\section{Internal reasons}

Similar to focus groups, internal reasons under the overarching theme of "health-related needs and motivators" encompassed the perceived need to do more physical activity, finding motivation, weight management, and the curiosity to see how they compared to others in terms of fitness and physical activity. As in the focus groups, the majority of the interviewed employees indicated their need to do more physical activity as their primary reason for signing up for the programme. Many said they enrolled because they wanted to increase their motivation to become more physically active, and many identified a need to lose weight as a further motivating factor for participation. Lastly, 10 out of 42 interviewees mentioned that they were curious to see what others were doing in terms of fitness and activity, and said they enrolled because they wanted to compare themselves with other participants.

\section{Programme-related reasons}

Among the reasons related to the characteristics of the programme, "programme attractiveness" theme was identified. Programme attractiveness encompassed the perceived interestingness, ease of use and accessibility of the programme, and the fact that it employed reminders (e-mails and SMS). Some employees indicated that they felt attracted by the "look and feel" of the information they saw about the programme (i.e., e-mail invitations and posters displayed in common areas). Moreover, many interviewees mentioned that they enrolled because they liked the idea of receiving reminders, which were seen as useful "extra incentives" for "making them think" about doing more physical activity. 


\section{External reasons}

Among external factors, the theme "recommendation" describes the fact that interviewees enrolled because they were recommended by a supervisor or by a colleague, who encouraged and reminded them to subscribe. Participants who worked in academic institutions reported that they enrolled because they wanted to support a research project conducted by a fellow institution (the theme was called "collegial spirit"). This suggested a sense of commitment to academic research and to help a fellow research institution.

\section{Reasons for non-participation (interviews)}

\section{Internal reasons}

Among internal reasons for not enrolment, two overarching themes emerged from the interviews: "living a busy life" and "loss of interest". Even though they were initially interested in the programme, almost all interviewees mentioned that, at the time when the programme was launched, they felt to have time constraints (e.g., family commitments, workload, etc.), which prevented them from completing enrolment. The "loss of interest" theme encompasses the idea that some employees realised that they were already doing enough physical activity as part of their daily routine, and thus believed that the programme was not relevant to them anymore.

\section{Programme-related reasons}

Similar to focus groups, two overarching themes were identified: "issues related to the enrolment process" and "issues with technology". These themes cross the internal and programme-related categories, as they are associated with both internal reasons and perceptions about programme characteristics. Because participants perceived themselves as having time constraints, some felt the enrolment process as being too time consuming and burdensome. Some others reported having experienced personal issues with technology, 
which made them lose patience with the technology upon which part of the programme was based (i.e., mobile phones) and did not complete the enrolment.

\section{External reasons}

Among external factors that might have discouraged participation, the theme "lack of follow-up" about programme participation was identified. Opposite to the theme "recommendation" for enrolled employees, this theme identifies the problems associated with the lack of organisational support and reminder about the enrolment. Two interviewees from the same workplace independently mentioned the fact that their supervisor had encouraged them to sign up when the recruitment started, but did not provide more information about the programme and then did not follow-up with them to confirm their participation. Because of this lack of follow-up, one employee forgot to complete the enrolment procedure and one reported that they had sought other methods of assistance in their goal to become more physically active.

\section{Discussion}

This paper examined the reasons for participating and not participating in a technologydelivered workplace physical activity intervention. The thematic framework derived from the works of Linnan et al. and King et al. allowed the identification of aspects upon which employees base their decisions of enrolling or not enrolling in a workplace PA intervention. This study confirms that employees are influenced in their decisions by a combination of internal motives and needs (e.g., need to do more, motivation, weight management, curiosity), programme characteristics and features (e.g., the use of reminders and perceived attractiveness), and external reasons (e.g., the role of employer in reminding about enrolling in the programme). The results are discussed according to the two overarching clusters of 
"reasons for participation" and "reasons for non-participation", and implications for workplace health improvement and research are considered.

\section{Reasons for participation}

Among internal reasons, the data show that employees enrolled in the programme because of health-related needs and motivators: they wanted to become more active, get motivated to be more active, be able to better manage their weight, and were curious to see their level of physical activity and thought to be able to compare it with others. In particular, the theme "need to do more" can be associated with positive beliefs about the beneficial role played by physical activity, which has been "associated with initial adoption of an exercise programme for both men and women" (King et al., 1992). Becoming more active and better managing weight were recurring themes both in focus groups and individual interviews. Consistent with other research in the field (Robroek et al., 2009, 2012), this result suggests that people who participate in these programmes have a specific interest in improving their personal health behaviours and should be provided with consistent information about the programme offer and contents. To increase participation, workplace health promotion programmes and PA interventions should conduct formative research to identify the segment of employees most interested in changing their behaviours, and understanding factors that motivate the target segment to engage in physical activity and enrol in a new intervention.

Among programme-related factors, employees enrolled because they were attracted by some characteristics of the programme. They perceived it as easy to use and accessible, and they liked the idea of receiving reminders for doing physical activity via email and text message. Ease of use and accessibility are considered key elements that need to be enhanced in general public health interventions using the Internet (Bennett and Glasgow, 2009). The attractive role of reminders is consistent with the literature reporting health promotion interventions using periodic prompts for behaviour change (Cole-Lewis and Kershaw, 2010; 
Déglise et al., 2012; Fry and Neff, 2009). The role of text messages in health promotion interventions (Fjeldsoe et al., 2009; Free et al., 2011; Sirriyeh et al., 2010; Wallace et al., 2011) suggests that future studies should continue employing these media and investigating their most effective use and adoption.

Amongst external factors, the programme being endorsed by a supervisor or by a colleague was considered an important motivator for enrolment. These results confirm the important role of the employer and potential influence of workplace health champions in promoting health promotion programmes in workplace settings (Blake and Lloyd, 2008; DeJoy et al., 2009; Edmunds et al., 2013; Heinen and Darling, 2009). Future studies in the workplace setting should carefully consider building and maintaining visible employer support for all phases of the programme, and actively engaging workplace health champions in promoting health improvement programmes. Employer support might be gained more easily if managers are involved in the design and planning phases of the intervention, and might play a crucial role especially in the promotion phase.

\section{Reasons for non-participation}

Major perceived barriers to enrolment were: lack of time to complete the enrolment procedures (i.e., submission of informed consent and online questionnaire) and to devote to the programme itself; loss of interest towards the programme from the time when they first saw or received promotional materials to the time when they started, but not completed, the baseline questionnaire; time and practical issues with the enrolment process; and lack of institutional support and follow-up. Employees did not enrol because they did "not have time to do any sort of things". Time constraints and lack of time are frequently reported in the literature as challenging factors negatively influencing participation in physical activity studies and as a barrier to participation in general WHPP (Chinn et al., 2006; Person et al., 2010), and in other workplace PA studies (Edmunds et al., 2013; Fletcher et al., 2008; Kruger 
et al., 2007; Phipps et al., 2010; Robroek et al., 2012). In this study, time limitations were both mentioned as barrier to participation and to were also related to the enrolment process, which appeared too time consuming and burdensome. It is unclear which aspects of the enrolment were perceived as time consuming or burdensome (e.g., Was the questionnaire too long? Was the whole procedure too complicated?), and this warrants further investigation. This suggests that health programme should be designed and implemented in a way that reduces the respondent burden by providing fast and simple enrolling procedures, and highlighting the minimal time input required both for enrolling in the intervention and for taking part, or being clear from the outset that some time commitment is required. Performing accurate formative research, using a user-centred approach, might allow better identification of solutions and situations for which the target audience would more likely enrol in similar health improvement programmes. Furthermore, user interface and usability testing prior to programme launch could highlight potential factors that may limit enrolment.

Employees did not participate in the study because they lost the interest in the programme before completing the enrolment process. Losing interest in the programme was reported as reason for non-participation in other studies, which found that losing interest was associated with the perception that employees were already healthy (Robroek et al., 2009, 2012) or that they were doing enough physical activity (Chinn et al., 2006; Groeneveld et al., 2009; Spittaels and De Bourdeaudhuij, 2007). This result confirms also that these programmes tend to attract an already active and healthy population. In fact, these employees who did not enrol the programme, de facto showed some initial interest towards the programme by submitting the informed consent and starting the baseline survey. Promotional efforts might need to explicit upfront to whom the programme is dedicated and the goals of these types of interventions (e.g., motivating individuals to increase their physical activity vs. maintaining current physical activity levels). Future research should try to identify the best persuasive 
communication strategies to attract those employees who are sedentary to participate in these interventions. More efforts should be invested into accurate target segmentation and analysis, so that programmes can reach those who may benefit the most.

Among the external factors for non-enrolment some employees reported that they did not complete the process because the employer did not follow-up with them or did not remind them to sign up, hence forgetting to subscribe. In cases when the organisational or managerial staff actively promoted the programme and encouraged employees to participate, they were more likely to subscribe. In the cases in which this situation did not happen, or when the managerial staff did not follow-up with employees, participants did not complete the enrolment. Not participating because of forgetting to subscribe was also reported in other research (Joslin et al., 2006; Robroek et al., 2012) and reinforces the importance of the role of employers in fostering employee participation in workplace health interventions (Blake and Lloyd, 2008; DeJoy et al., 2009; Edmunds et al., 2013; Heinen and Darling, 2009). Programme managers might need to ensure that there is an optimal balance between encouraging employers to follow-up and actively promoting the programme among their employees, while respecting the individuals' confidentiality and autonomous decisions to participate or not participate. At the same time this reinforces the need to provide simple and easy procedures to complete enrolment so that employers are not required to continuously remind their employees to participate in interventions.

We identified several internal, programme-related and external reasons for participation and non-participation, but these results should be interpreted bearing in mind some limitations. The sampling procedures did not allow us to differentiate between employees with different levels of activity, or socio-cognitive determinants of PA, since we did not have these data available for screening or eligibility criteria. The data from the intervention were outdated as physical activity patterns might change over a long period of time. Including these 
aspects might help provide a deeper understanding of the moderating factors that influence participation in future studies. Interviewees might have also self-selected themselves to participate in the interviews, motivated by the same initial interest towards the programme. Their responses reflected their unique and personal views and might differ from those of participants who did not agree to be interviewed, and from those who were not interested in participating in the programme. Some reasons might not have emerged due to recall issues, due to the timeframe between the end of the intervention and the interviews. Even though the interviewees were prompted with materials used for promoting the intervention, participants may potentially have failed to recall details and specific reasons for enrolment or attrition.

\section{Conclusion}

Our results suggest that workplace physical activity interventions should be designed accounting for individual-level aspects, programme-based and external reasons. Hence, it would be important to identify salient motivators (e.g., need to lose weight, do more activity, etc.) and barriers to participation through formative research with the target population and target segmentation. Programme enrolment procedures should be simplified as much as possible and not time consuming, so that burden on participants is reduced and early attrition is minimised. Moreover, the employer should find ways to actively promote WHPPs to their staff while also maintaining confidentiality and individual rights on employees, so that larger segments of the workforce can be reached.

\section{References}

Abraham, C. and Graham-Rowe, E. (2009), “Are worksite interventions effective in increasing physical activity? A systematic review and meta-analysis", Health Psychology Review, pp. 108-144. 
Ajzen, I. (1991), “The Theory of Planned Behavior", Organizational Behavior and Human Decision Processes, Vol. 50, pp. 179-211.

Bennett, G.G. and Glasgow, R.E. (2009), "The delivery of public health interventions via the Internet: actualizing their potential”, Annual Review of Public Health, Vol. 30, pp. 273292.

Blake, H. and Lloyd, S. (2008), "Influencing organisational change in the NHS: lessons learned from workplace wellness initiatives in practice", Quality in Primary Care, Vol. 16 No. 6, pp. 449-455.

Bull, F.C., Adams, E.J. and Hooper, P.L. (2008), Well@Work: Promoting active and healthy workplaces final evaluation report, Loughborough, UK: School of Sport and Exercise Sciences, Loughborough University, UK, available at: http://www.bhfactive.org.uk/downloads/W@W_EVALUATION_REPORT.pdf.

Chinn, D.J., White, M., Howel, D., Harland, J.O.E. and Drinkwater, C.K. (2006), "Factors associated with non-participation in a physical activity promotion trial”, Public Health, Vol. 120 No. 4, pp. 309-319.

Cole-Lewis, H. and Kershaw, T. (2010), “Text Messaging as a Tool for Behavior Change in Disease Prevention and Management”, Epidemiologic Reviews, Vol. 32 No. 1, pp. 56 69.

Conn, V.S., Hafdahl, A.R., Cooper, P.S., Brown, L.M. and Lusk, S.L. (2009), "Meta-analysis of workplace physical activity interventions", American Journal of Preventive Medicine, Vol. 37 No. 4, pp. 330-339.

Déglise, C., Suggs, L.S. and Odermatt, P. (2012), "Short message service (SMS) applications for disease prevention in developing countries", Journal of Medical Internet research, Vol. 14 No. 1, p. e3. 
DeJoy, D.M., Bowen, H.M., Baker, K.M., Bynum, B.H., Wilson, M.G., Goetzel, R.Z. and Dishman, R.K. (2009), “Management support and worksite health promotion program effectiveness", (Karsh, B.T.,Ed.)Ergonomics and Health Aspects of Work with Computers, Lecture Notes in Computer Science, Vol. 5624, pp. 13-22.

Dishman, R.K., Oldenburg, B., O’Neal, H.A. and Shephard, R.J. (1998), “Worksite physical activity interventions", American Journal of Preventive Medicine, Vol. 15 No. 4, pp. $344-361$.

Dishman, R.K., Sallis, J.F. and Orenstein, D.R. (1985), “The determinants of physical activity and exercise", Public Health Reports, Vol. 100 No. 2, p. 158.

Edmunds, S., Hurst, L. and Harvey, K. (2013), "Physical activity barriers in the workplace: An exploration of factors contributing to non-participation in a UK workplace physical activity intervention", International Journal of Workplace Health Management, Vol. 6 No. 3, pp. 227-240.

Fanning, J., Mullen, S.P. and McAuley, E. (2012), “Increasing Physical Activity With Mobile Devices: A Meta-Analysis”, Journal of Medical Internet Research, Vol. 14 No. 6, p. e161.

Fjeldsoe, B.S., Marshall, A.L. and Miller, Y.D. (2009), "Behavior Change Interventions Delivered by Mobile Telephone Short-Message Service”, American Journal of Preventive Medicine, Vol. 36 No. 2, pp. 165-173.

Fletcher, G.M., Behrens, T.K. and Domina, L. (2008), "Barriers and enabling factors for work-site physical activity programs: a qualitative examination", Journal of Physical Activity \& Health, Vol. 5 No. 3, pp. 418-429.

Free, C., Knight, R., Robertson, S., Whittaker, R., Edwards, P., Zhou, W., Rodgers, A., et al. (2011), "Smoking cessation support delivered via mobile phone text messaging (txt2stop): a single-blind, randomised trial", The Lancet, Vol. 378 No. 9785, pp. 49-55. 
Fry, J.P. and Neff, R.A. (2009), "Periodic prompts and reminders in health promotion and health behavior interventions: systematic review", Journal of Medical Internet Research, Vol. 11 No. 2.

Geraghty, A.W.A., Torres, L.D., Leykin, Y., Pérez-Stable, E.J. and Muñoz, R.F. (2013), "Understanding attrition from international internet health interventions: a step towards global eHealth", Health Promotion International, Vol. 28 No. 3, pp. 442-452.

Groeneveld, I.F., Proper, K.I., Beek, A.J. van der, Hildebrandt, V.H. and van Mechelen, W. (2009), "Factors associated with non-participation and drop-out in a lifestyle intervention for workers with an elevated risk of cardiovascular disease", International Journal of Behavioral Nutrition and Physical Activity, Vol. 6 No. 1, p. 80.

Heinen, L. and Darling, H. (2009), “Addressing Obesity in the Workplace: The Role of Employers", Milbank Quarterly, Vol. 87 No. 1, pp. 101-122.

Joslin, B., Lowe, J.B. and Peterson, N.A. (2006), "Employee characteristics and participation in a worksite wellness programme", Health Education Journal, Vol. 65, pp. 308-319.

Kaewthummanukul, T. and Brown, K.C. (2006), "Determinants of employee participation in physical activity: critical review of the literature", AAOHN Journal: Official Journal of the American Association of Occupational Health Nurses, Vol. 54 No. 6, pp. 249-261.

King, A.C., Blair, S.N., Bild, D.E., Dishman, R.K., Dubbert, P.M., Marcus, B.H., Oldridge, N.B., et al. (1992), "Determinants of physical activity and interventions in adults", Medicine and Science in Sports and Exercise, Vol. 24 No. 6, Suppl, pp. S221-S236.

Kruger, J., Yore, M.M., Bauer, D.R. and Kohl, H.W. (2007), "Selected barriers and incentives for worksite health promotion services and policies", American Journal of Health Promotion, Vol. 21 No. 5, pp. 439-447. 
Lakerveld, J., IJzelenberg, W., Tulder, M.W. van, Hellemans, I.M., Rauwerda, J.A., Rossum, A.C. van and Seidell, J.C. (2008), "Motives for (not) participating in a lifestyle intervention trial”, BMC Medical Research Methodology, Vol. 8 No. 1, p. 17.

Laws, R.A., Fanaian, M., Jayasinghe, U.W., McKenzie, S., Passey, M., Davies, G.P., Lyle, D., et al. (2013), "Factors influencing participation in a vascular disease prevention lifestyle program among participants in a cluster randomized trial", BMC Health Services Research, Vol. 13 No. 1, p. 201.

Linnan, L.A., Sorensen, G., Colditz, G.A., Klar, D.N. and Emmons, K.M. (2001), “Using theory to understand the multiple determinants of low participation in worksite health promotion programs", Health Education \& Behavior, Vol. 28 No. 5, pp. 591-607.

Maibach, E.W. and Parrott, R. (1995), Designing health messages: approaches from communication theory and public health practice, Sage Publications, Thousand Oaks, CA.

Malik, S., Blake, H. and Suggs, L.S. (2013), “A systematic review of workplace health promotion interventions for increasing physical activity.", British Journal of Health Psychology, doi:10.1111/bjhp.12052.

Marcus, B.H., Williams, D.M., Dubbert, P.M., Sallis, J.F., King, A.C., Yancey, A.K., Franklin, B.A., et al. (2006), "Physical activity intervention studies: what we know and what we need to know: a scientific statement from the American Heart Association Council on Nutrition, Physical Activity, and Metabolism (Subcommittee on Physical Activity); Council on Cardiovascular Disease in the Young; and the Interdisciplinary Working Group on Quality of Care and Outcomes Research”, Circulation, Vol. 114 No. 24, pp. 2739-2752.

Marshall, A.L. (2004), "Challenges and opportunities for promoting physical activity in the workplace”, Journal of Science and Medicine in Sport, Vol. 7 No. 1, Supplement 1, p. 60. 
Onwuegbuzie, A.J. and Collins, K.M.. (2007), “A typology of mixed methods sampling designs in social science research", The Qualitative Report, Vol. 12 No. 2, pp. 281-316.

Person, A.L., Colby, S.E., Bulova, J.A. and Eubanks, J.W. (2010), "Barriers to participation in a worksite wellness program", Nutrition Research and Practice, Vol. 4 No. 2, p. 149.

PHE, Public Health England. (2013), Our priorities for 2013/14 (Publication No. 2013007), London: Public Health England, available at:

http://www.dh.gov.uk/en/Publicationsandstatistics/Publications/PublicationsPolicyAndG uidance/DH_4105354 (accessed 22 October 2011).

Phipps, E., Madison, N., Pomerantz, S.C. and Klein, M.G. (2010), "Identifying and Assessing Interests and Concerns of Priority Populations for Work-Site Programs to Promote Physical Activity", Health Promotion Practice, Vol. 11 No. 1, pp. 71-78.

Ritchie, J. and Lewis, J. (2003), Qualitative research practice: A guide for social science students and researchers, Sage Publications, Thousand Oaks, CA.

Robinson, K.L., Driedger, M.S., Elliott, S.J. and Eyles, J. (2006), “Understanding Facilitators of and Barriers to Health Promotion Practice”, Health Promotion Practice, Vol. 7 No. 4 , pp. $467-476$.

Robroek, S., van Lenthe, F., van Empelen, P. and Burdorf, A. (2009), "Determinants of participation in worksite health promotion programmes: a systematic review", International Journal of Behavioral Nutrition and Physical Activity, Vol. 6 No. 1, p. 26.

Robroek, S.J., Lindeboom, D.E. and Burdorf, A. (2012), "Initial and Sustained Participation in an Internet-delivered Long-term Worksite Health Promotion Program on Physical Activity and Nutrition”, Journal of Medical Internet Research, Vol. 14 No. 2, p. e43.

Robroek, S.J.W., Brouwer, W., Lindeboom, D.E.M., Oenema, A. and Burdorf, A. (2010), "Demographic, Behavioral, and Psychosocial Correlates of Using the Website 
Component of a Worksite Physical Activity and Healthy Nutrition Promotion Program: A Longitudinal Study", Journal of Medical Internet Research, Vol. 12 No. 3, p. e44.

Sandelowski, M. (2000), “Combining qualitative and quantitative sampling, data collection, and analysis techniques in mixed-method studies", Research in Nursing \& Health, Vol. 23 No. 3, pp. 246-255.

Sirriyeh, R., Lawton, R. and Ward, J. (2010), "Physical activity and adolescents: an exploratory randomized controlled trial investigating the influence of affective and instrumental text messages", British Journal of Health Psychology, Vol. 15 No. Pt 4, pp. $825-840$.

Soler, R.E., Leeks, K.D., Razi, S., Hopkins, D.P., Griffith, M., Aten, A., Chattopadhyay, S.K., et al. (2010), “A systematic review of selected interventions for worksite health promotion", American Journal of Preventive Medicine, Vol. 38 No. 2S, pp. S237-S262.

Spittaels, H. and De Bourdeaudhuij, I. (2007), "Who participates in a computer-tailored physical activity program delivered through the Internet? A comparison of participants' and non-participants' characteristics", International Journal of Behavioral Nutrition and Physical Activity, Vol. 4 No. 1, p. 39.

Spittaels, H., De Bourdeaudhuij, I. and Vandelanotte, C. (2007), "Evaluation of a websitedelivered computer-tailored intervention for increasing physical activity in the general population”, Preventive Medicine, Vol. 44 No. 3, pp. 209-217.

To, Q.G., Chen, T.T.L., Magnussen, C.G. and To, K.G. (2013), “Workplace Physical Activity Interventions: A Systematic Review", American Journal of Health Promotion, p. 130430133253002.

Tuckett, A.G. (2004), "Qualitative research sampling: the very real complexities”, Nurse Researcher, Vol. 12 No. 1, pp. 47-61. 
Wallace, P., Murray, E., McCambridge, J., Khadjesari, Z., White, I.R., Thompson, S.G., Kalaitzaki, E., et al. (2011), “On-line Randomized Controlled Trial of an Internet Based Psychologically Enhanced Intervention for People with Hazardous Alcohol Consumption”, PLoS ONE, Vol. 6 No. 3, p. e14740. 


\section{Tables}

Table 1. Demographics of employees who enrolled and did not enrol in the programme

\begin{tabular}{|c|c|c|c|c|}
\hline & \multicolumn{3}{|c|}{ Enrolled employees } & \multirow{2}{*}{$\begin{array}{c}\text { Non-enrolled } \\
\text { employees } \\
\text { Interviews } \\
(\mathrm{n}=9)\end{array}$} \\
\hline & $\begin{array}{c}\text { Interviews } \\
(\mathrm{n}=42)\end{array}$ & $\begin{array}{c}\text { Focus groups } \\
(\mathrm{n}=11)\end{array}$ & $\begin{array}{c}\text { Total } \\
(\mathrm{n}=53)\end{array}$ & \\
\hline \multicolumn{5}{|l|}{ Gender } \\
\hline Female & 31 & 9 & 40 & 6 \\
\hline Male & 11 & 2 & 13 & 3 \\
\hline \multicolumn{5}{|l|}{ Age groups* } \\
\hline 20-29 years & 8 & 1 & 9 & 1 \\
\hline 30-39 years & 9 & 2 & 11 & 3 \\
\hline 40-49 years & 15 & 3 & 18 & 3 \\
\hline $50-63$ years & 10 & 5 & 15 & 2 \\
\hline \multicolumn{5}{|l|}{ Intervention group } \\
\hline E-mail only & 22 & 7 & 29 & $\mathrm{n} / \mathrm{a}$ \\
\hline E-mail plus SMS & 20 & 4 & 24 & $\mathrm{n} / \mathrm{a}$ \\
\hline \multicolumn{5}{|l|}{ Education level } \\
\hline Higher degree & 30 & 6 & 36 & $\mathrm{n} / \mathrm{a}$ \\
\hline A level or equivalent & 5 & 2 & 7 & $\mathrm{n} / \mathrm{a}$ \\
\hline $\begin{array}{l}\text { Other professional } \\
\text { qualification }\end{array}$ & 5 & 3 & 8 & $\mathrm{n} / \mathrm{a}$ \\
\hline O-Level passes/GCSE & 2 & - & 2 & $\mathrm{n} / \mathrm{a}$ \\
\hline \multicolumn{5}{|l|}{ Workplace type } \\
\hline Universities & 35 & - & 35 & 7 \\
\hline Colleges & 1 & 6 & 7 & - \\
\hline Service companies (SMEs) & 4 & - & 4 & 2 \\
\hline Petrochemical companies & 1 & 5 & 6 & - \\
\hline Borough councils & 1 & - & 1 & - \\
\hline \multicolumn{5}{|l|}{ Work status } \\
\hline Full time $(80-100 \%)$ & 33 & 11 & 44 & $\mathrm{n} / \mathrm{a}$ \\
\hline Part-time $(50-70 \%)$ & 7 & - & - & $\mathrm{n} / \mathrm{a}$ \\
\hline Part-time $(25 \%)$ & 2 & - & - & $\mathrm{n} / \mathrm{a}$ \\
\hline \multicolumn{5}{|l|}{ Family status } \\
\hline Single, with no kids & 12 & 1 & 13 & $\mathrm{n} / \mathrm{a}$ \\
\hline Single, with kids & 2 & - & - & $\mathrm{n} / \mathrm{a}$ \\
\hline Couple, with no kids & 13 & 5 & 18 & $\mathrm{n} / \mathrm{a}$ \\
\hline Couple, with kids & 15 & 5 & 20 & $\mathrm{n} / \mathrm{a}$ \\
\hline
\end{tabular}

Notes: Mean age for individual employees: 41 years $(\mathrm{SD}=11$, range: $21-63)$; Mean age for males $=46$ years $(\mathrm{SD}=11$, range: 28 -62); Mean age for females $=39$ years ( $\mathrm{SD}=11$, range: $21-63)$; Mean age for focus group participants: 44 years $(\mathrm{SD}=11$, range: $25-60)$; Mean age for males $=39(\mathrm{SD}=11.2$, range: $25-53)$; Mean age for females $=45(\mathrm{SD}=9$, range $33-60)$.

Notes: Mean age for non-enrolled employees: 36 years $(\mathrm{SD}=11$, range: $22-51)$; Mean age for males $=36$ years $(\mathrm{SD}=14$, range: $25-51)$; Mean age for females $=36$ years $(\mathrm{SD}=11$, range: $22-50)$. 
Table 2. Typology and illustrative examples of themes emerged from focus groups and interviews

\section{Focus groups/interviews}

Focus groups with enrolled employees $(n=11)$
Internal reasons

\section{Health-related needs and motivators}

Weight management:

"Everybody in my family is healthy and fit and sporty except myself. So everything I was getting then, [it was] to increase my fitness level altogether. So I went to the Xxxxx because it was something I could do at work, read through the lunch hour, you know".

Motivation: "I spend most of my days at a desk. So I joined the programme to get a bit more motivation to do more exercise. And that's it I think, basically".
Programme-related reasons

\section{Programme attractiveness}

Reminders (1): "I wanted to get

fitter and lose some weight and by getting the e-mails that we got it would sort of motivate me to do that all the more".

Reminders (2): "I did this because it would give you the incentive that you get an e-mail on a weekly basis, something that I haven't been experiencing before. We also got it about probably at the same time as this [other workplace health promotion programme] came out, so it came quite timely... [it was] adding quite nicely to the exercise and getting prompted for the difficulty as well."
Interviews with enrolled employees $(n=42)$

\section{Health-related needs and motivators}

Need to do more (1): "I needed to do it. It's not just something that, you know, was easy for me. I wasn't doing enough for long before then. Well, [I wasn't doing any] structured sort of exercise if, you like. So I thought that it was

\section{Programme attractiveness}

Interestingness: "It just looked quite interesting, the idea of receiving little messages to tell you to do things ...

[I was interested in] the idea of being told what to do, you know, being sent messages by people telling you to do things... and I thought that it might be interesting."

\section{External reasons}

\section{Recommendation (implicit):}

Endorsement by workplace health champions that exerted their personal influence to convince their colleagues to sign up for the programme.
Recommendation: "It was a friend that recommended it last time we see: she had seen the posters and recommended it to me, because she knew I might have been interested".

\section{Collegiate spirit (in academic} institutions): "Well, we do a lot of work with other universities anyway, 
just to have a good kick-start to do it, you know".

Need to do more (2): "I think the main reason was because I spent my working day stationary, I mean, [I have] quite a stressful job and I won't be doing anything other than sitting down at my desk. I didn't really want to go for a walk... You know, things like that. [So I wanted] to do more... normal everyday movement."

Motivation: "I needed a bit of a push, just needed a bit of a kick on the backside I suppose to make to start thinking about it".

Weight management: "I was overweight at the time - I still am anyway, so... it was the fact that I knew that at the end of the programme I would probably feel better about myself and I would lost a couple of pounds and I mean that $5 \%$ weight loss its benefits are have been well documented. So for me that was the motivating factor".

Curiosity: "[I enrolled] basically
Ease of use and accessibility: "The other key thing of course was that it was online. So it was immediately accessible and available... and I could work with the idea of getting the e-mail every now and then, to

kind remind me about what I should be doing and to keep me kind of focused on it. And so I think it was primarily the accessibility, the ease of use of the information as it was provided".

Reminders: "[I subscribed] to get the reminders, because if you're sat, if you are in a lunch break and you're sat at your desk just on the Internet and you're not moving and you're eating something that's not that good and then you get a reminder and it's just: 'have a walk!', or something. Straight away there is a trigger in your mind and you think: 'yeah, that's right, I can do that!'”.

Interestingness: "It just looked quite interesting to you know, the idea of receiving little messages to tell you to do things and I was just interested in participating. I suppose [I was interested in] the idea of being told what to do, you know, being sent you know, so if Yyyyy e-mailed us, it would be good to help and viceversa. Well, if they need people to do it... You know, we... we try to help... universities generally try and help each other with stuff and... So I felt a little responsibility to do that". 
because it was asking for information about people's

activity levels and... I was sort of be interesting".

curious as how they were doing,

benchmarking, if you like, on

people's fitness levels and what sort of criteria they were using to measure what we're doing and really to see where I was in terms of my own level of physical fitness and ability".

Interviews with non-enrolled employees $(n=9)$

\section{Living a busy life}

Time constraints (1): "I didn't

sign up or I didn't do the programme for any other reason than simply due to constraints on my time and difficulties on my time, otherwise I think I would have gladly welcomed the participation. I work full time, and I've issues with my personal life, so I didn't really have a huge amount of time to do any sort of things..."

Time constraints (2): "I had a lot of stuff going on at that time and I was getting a lot of the emails and I think it just got on the stage where I just didn't open the -emails. I don't think I've [opened] any of them." messages by people telling you to do things... and I thought that it might

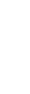




\section{Loss of interest}

Not relevant: "I just decided it

wasn't worth my while because I cycle fifteen miles a day so, you know, I probably couldn't do much more exercise anyway. I've got my own exercise routine”.
"I can remember trying to sign up, because I didn't get actually signed

up, that's what [happened]. And then

I changed my phone after that, which is probably why I didn't get... if you

had sent me stuff I wouldn't have had it because I didn't use the other phone. [...] I sort of went round in circles with my phone, it didn't seem to do anything or get anywhere and I gave up, really. I just kind of lost patience with the technology rather than [with] the programme". 